\title{
Effect of the distribution density of biomass combined heat and power plant networks on total energy utilization efficiency
}

Yifei Zhang, and Jian Kang

Citation: Journal of Renewable and Sustainable Energy 10, 065902 (2018); doi: 10.1063/1.5037244

View online: https://doi.org/10.1063/1.5037244

View Table of Contents: http://aip.scitation.org/toc/rse/10/6

Published by the American Institute of Physics

\section{Articles you may be interested in}

Energy management strategy for integrating photovoltaic energy in AC microgrid Journal of Renewable and Sustainable Energy 10, 065102 (2018); 10.1063/1.5022507

Performance estimation of Savonius wind and Savonius hydrokinetic turbines under identical power input Journal of Renewable and Sustainable Energy 10, 064704 (2018); 10.1063/1.5054075

Effects of penetration level and location of wind turbines on shadow prices and congestion of transmission lines Journal of Renewable and Sustainable Energy 10, 065503 (2018); 10.1063/1.5033948

Utilization of ICE exhaust gas as a heat source for pyrolysis of natural rubber as automobile fuel Journal of Renewable and Sustainable Energy 10, 064701 (2018); 10.1063/1.5045246

Characteristic analysis of operation curve of energy storage system considering typical weather conditions to suppress photovoltaic power fluctuation

Journal of Renewable and Sustainable Energy 10, 063502 (2018); 10.1063/1.5054391

Local variability of yield and physical properties of açaí waste and improvement of its energetic attributes by separation of lignocellulosic fibers and seeds

Journal of Renewable and Sustainable Energy 10, 053102 (2018); 10.1063/1.5027232

\section{Don't let your writing keep you from getting published!}




\title{
Effect of the distribution density of biomass combined heat and power plant networks on total energy utilization efficiency
}

\author{
Yifei Zhang ${ }^{1, a)}$ and Jian Kang ${ }^{1,2}$ \\ ${ }^{1}$ School of Architecture, Harbin Institute of Technology, Heilongjiang Cold Region \\ Landscape Science Key Laboratory, No. 66 Xidazhi Street, Harbin, China \\ ${ }^{2}$ School of Architecture, University of Sheffield, Sheffield S10 2TN, United Kingdom
}

(Received 22 April 2018; accepted 6 November 2018; published online 28 November 2018)

Combined heat and power (CHP) plants fueled by biomass can meet heating and power requirements for cold regions in winter. The objective of this research is to investigate the effect of the distribution density of biomass CHP plant networks on the total (heat and electricity) energy utilization efficiency. The distribution density is determined from the heat transmission threshold. The total energy utilization efficiency is determined from the demand distribution, the output efficiency, and the transmission losses of heat and electricity. To determine a suitable heat transmission threshold, a biomass CHP plant network model is derived to compare various candidate network plans with various heat transmission thresholds. Geographic information system software is employed to calculate the above factors, and the total energy utilization efficiencies of the various plans are compared. The results show that when the heat transmission threshold is low, the plant distribution density is high, and the size (capacity) of the CHP plants is small. Conversely, when the heat transmission threshold is high, the plant density is low and the size of the plants is large. A heat transmission threshold of $10 \mathrm{~km}$ results in a plant density that produces the greatest total energy utilization efficiency. Published by AIP Publishing.

https://doi.org/10.1063/1.5037244

\section{INTRODUCTION}

Biomass is the only storable and renewable form of energy. ${ }^{1}$ Methods to effectively utilize biomass energy and reduce consumption of nonrenewable energy sources are being investigated in many countries. ${ }^{2}$ The total installed capacity of biomass power generation worldwide increased by $10 \%$ from 2013 to 2014. China, Brazil, and certain regions of the United States were largely responsible for this increase. Europe remains the largest biomass and waste-toenergy power generation market, where the total installed capacity in 2014 reached $27.6 \mathrm{GW}$. Overall, the installed capacities of biomass power generation in the United States and Brazil in 2014 were $13.7 \mathrm{GW}$ and $13.5 \mathrm{GW}$, respectively, placing them second and third in the global ranking. China ranked fourth with $10.7 \mathrm{GW}$, but the growth rate was higher ${ }^{3}$ (Fig. 1). Improving the efficiency of utilization via asset planning has been an important topic in biomass energy generation. ${ }^{4}$

An assessment performed by Zhao ${ }^{5}$ showed that the maximal potential biomass energy productions in China are estimated to be 18833 and 24901 PJ in 2030 and 2050, respectively, using all means of biomass utilization. Rosillo demonstrated that all means of biomass utilization (including burning, thermochemical, biochemical, chemical, and physicochemical methods) have their shortcomings, and it is wise to choose a suitable method according to local conditions. ${ }^{6}$ Chen et $a l .{ }^{7}$ found that third-generation technology for biomass liquefied gas fuel production has higher energy conversion efficiency; however, low temperatures in winter in cold

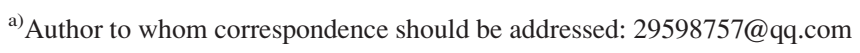




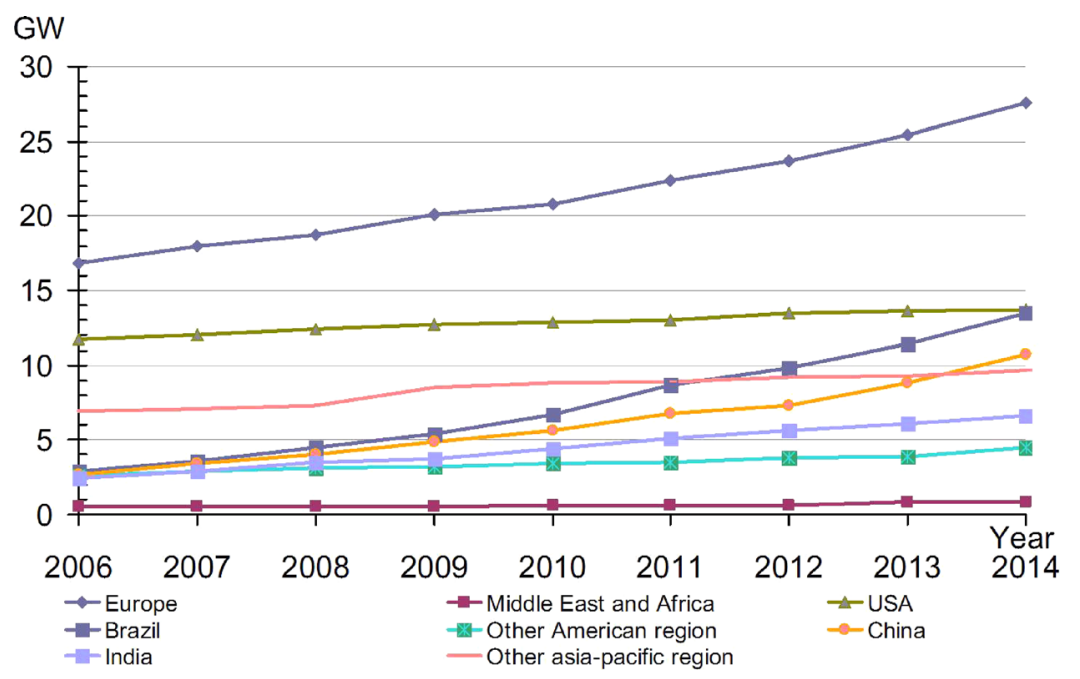

FIG. 1. Overall installed capacity of biomass and waste-to-energy power generation worldwide, 2006-2014 (GW).

regions severely reduce the efficiency. Göran ${ }^{8}$ found that the energy conversion efficiency (energy processing output/energy processing inputs $\times 100 \%$ ) of power generation by the direct combustion of biomass is similar to that of solid fuel production. However, the cost of producing solid fuel from biomass is higher, and so, the direct combustion of biomass in cold regions is more economical. Blaschke et al. ${ }^{9}$ studied renewable energy site selection. The authors calculated the energy demand distribution based on regional population distribution data and determined the required capacity of planned biomass power generation plants in a certain region. Shi et al. ${ }^{10}$ analyzed regional road networks using geographic information system (GIS) tools, defined a series of weights and thresholds to calculate the biomass raw material transport costs, and identified the optimal distribution density of biomass power generation plants in a certain region. This analysis assumed only power generation plants, not combined heat and power (CHP) plants. Therefore, this analysis is unsuitable for cold regions. $\mathrm{Lu}$ and $\mathrm{Xi}^{11}$ investigated the relationship between heat transmission losses and the total pipe length in the heat distribution network. They determined that when the heat distribution network transmission distance does not exceed $20 \mathrm{~km}$, the heat loss increases in direct proportion to the transmission distance. Zhang and Kang ${ }^{12}$ employed the software program ArcGIS to analyze population and geographical distribution data. They assumed various levels of the heat transmission threshold and studied the effect of the biomass CHP plant network distribution density on the heat utilization efficiency.

The aforementioned studies have shown that biomass CHP plant network distribution density affects heat utilization efficiency. A natural question is whether plant network distribution density affects electricity utilization efficiency or total energy (heat and electricity) utilization efficiency. The answer to this question has direct implications for the economic efficiency of biomass energy systems in rural areas. No comprehensive research has been conducted on this topic.

The goal of this study is to investigate the effect of biomass CHP plant network distribution density on total energy utilization efficiency in rural areas for the purposes of planning. The effects of the energy demand distribution, heat output efficiency (heat processing output/ energy processing inputs $\times 100 \%$ ), heat transmission losses, electricity output efficiency (electricity processing output/energy processing inputs $\times 100 \%$ ), and electricity transmission losses are studied in detail. GIS software is employed to analyze geographically related data for factors such as the community distribution, population density, and locations of roads. Various heat transmission thresholds are defined to generate biomass CHP plant network plans. The heat transmission threshold that maximizes the biomass CHP plant network energy utilization efficiency is identified by comparing the various plans. Although the previous study ${ }^{12}$ has some 
results on heat efficiency, additional power energy will make analysis results inconclusive, and so, it is necessary to recalculate heat transmission thresholds for the total energy utilization efficiency. The results of this article show that when the research target changes, the values of heat transmission thresholds will also be different.

\section{METHODS: BUILDING THE BIOMASS CHP PLANT NETWORK MODEL}

Electric utilities normally calculate transmission losses using statistics, although fluctuations are small, and the values are generally constant. Therefore, this study focused on heat transmission losses. The transmission losses and the distribution network pipe length are directly related. The pipe length has limits and cannot increase infinitely. This limit is closely related to the heat transmission losses (heat transmission threshold), and the study of this relation is an important part of the present work.

\section{A. Design of networks based on the heat transmission threshold}

The heat transmission threshold reflects the heat transmission losses and the transmission distances, ${ }^{13}$ which affects the bounds of the biomass CHP plant service area ${ }^{14}$ and the economic efficiency. ${ }^{15}$ As shown in Fig. 2, when a biomass CHP plant is constructed for existing communities, the primary concern is whether the CHP plant can provide a certain minimal heat transmission efficiency over the plant service area. Because the heat transmission losses and the transmission distance are related, a limit on the efficiency is equivalent to a limit on the total pipe length of the distribution network from the CHP plant to the consumers. In Fig. 2, the dashed line represents the straight-line distance from the CHP plant to a community $(D)$. Under most circumstances, the pipes will not follow this path. Normally, pipes are laid along existing roads to reduce costs. The heat distribution pipe length is the length used for calculating the heat transmission threshold $(T)$. Because the roads are often circuitous, the analysis includes a road nonlinearity coefficient $N$, where $N=T / D$. Given the road nonlinearity coefficient, the biomass CHP plant service area is fixed. If the service area is defined by a circle, then, in theory, the radius is given by $(0, T]$. This result shows that the heat transmission threshold $(T)$ is an important parameter in biomass CHP plant network construction.

\section{B. Model factors and network topology}

The heat transmission threshold $(T)$ represents the length of the distribution pipes from the supply (CHP plant) to the consumer (community). Because the route is irregular (i.e., nonlinear), a road nonlinearity coefficient $(N)$ is included. ${ }^{16}$ A model of the biomass CHP plant that includes the heat transmission threshold, the road nonlinearity coefficient, and the distance

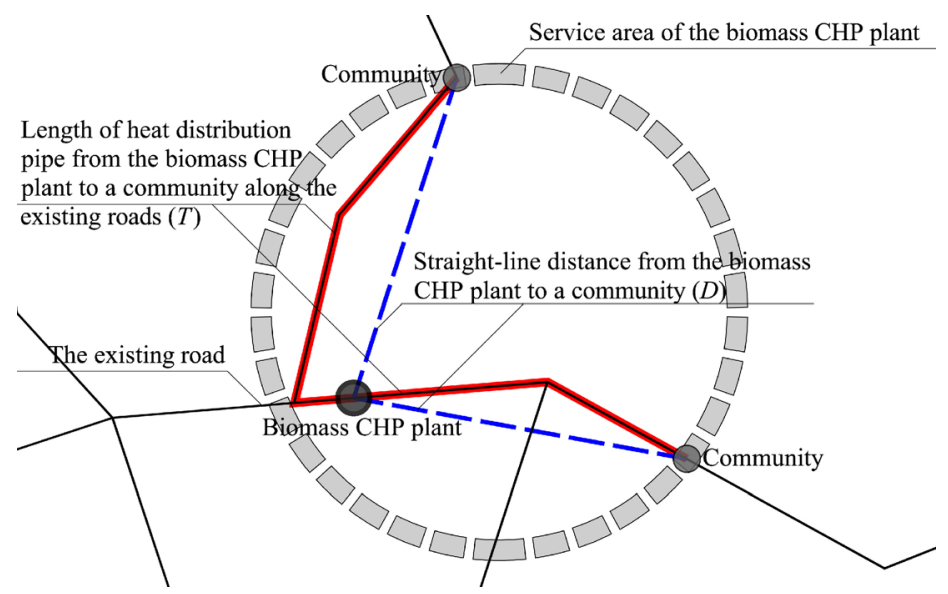

FIG. 2. Example of a biomass CHP plant network. 
between the community and the biomass CHP plant can be obtained. In the model, the average service radius of the biomass CHP plant is $T / N$. If the biomass CHP plants are equally distributed, then the distance between adjacent CHP plants is $2 \cot 30^{\circ} T / N$. The topology of the biomass CHP plant network under these ideal conditions is similar to a honeycomb, as shown in A1 in Fig. $3{ }^{17}$

The heat transmission threshold determines the topology of the network. However, structures that are more complex can emerge because of other factors such as the community distribution density and variations in the population distribution. These two factors affect the biomass CHP plant network topology in different aspects and could result in a hybrid structure in which these two factors interact.

The community distribution density affects the network topology under ideal conditions and results in an incomplete structure based on ideal assumptions. When the community distribution density is low, certain areas will have no customers, as shown in A2 of Fig. 3. In this situation, these areas do not require a CHP plant, and the network, which was formed based on ideal assumptions, is no longer a honeycomb. As the community distribution density decreases further, multiple areas will not require a CHP plant. A discontinuous and irregular structure is obtained, as shown in A3 in Fig. 3. Furthermore, the service area boundaries of the CHP plants adjacent to the vacant areas change from hexagons to circles.

Variations in the population distribution are another important factor affecting the network topology under ideal conditions. These variations affect the network topology and the plant size. The population distribution variations occur in two types. One type is geographical variations, and the other is population variations within each community. The first type results in offsets and distortions in the regular honeycomb network, as shown in B1 in Fig. 3. The second type results in power generation capacity differences among CHP plants in the network, as shown in $\mathrm{C} 1$. In addition, the routing of the heat distribution pipes and the electricity

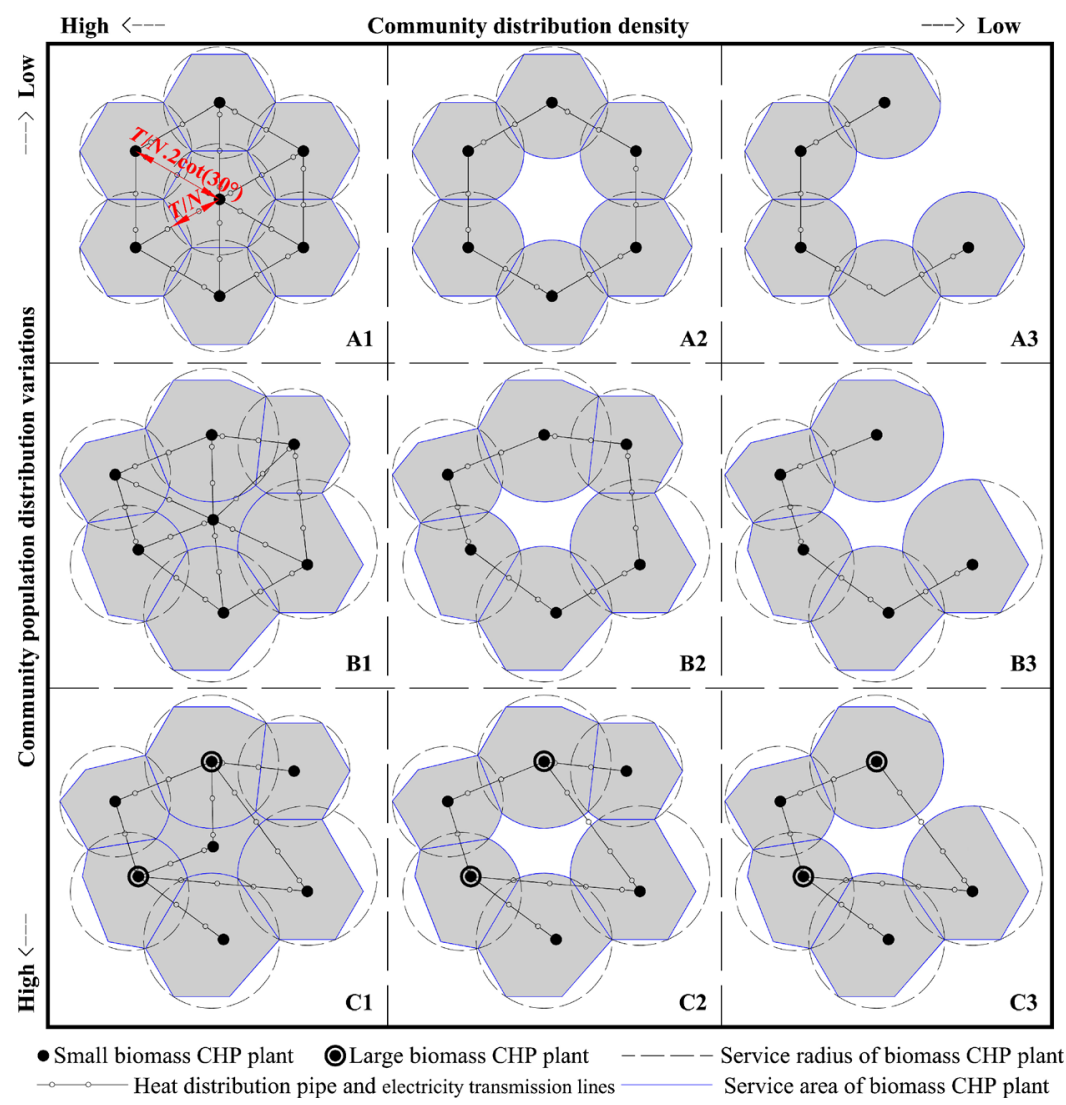

FIG. 3. Variants of a biomass CHP plant network. 
transmission lines from the CHP plants, which originate from the population centers, change accordingly.

To summarize, variations in the community distribution density and the population distribution affect the network topology in different ways, and these two factors affect each other. In Fig. 3, the rows (A1-A2-A3, B1-B2-B3, and $\mathrm{C} 1-\mathrm{C} 2-\mathrm{C} 3$ ) show the effect of the community distribution density on the network topology, and the columns (A1-B1-C1, A2-B2-C2, and A3-B3-C3) show the effect of the community population distribution variations on the network topology. In reality, both factors normally are present and exert their influence simultaneously. In Fig. 3, the various conditions represented in the nine graphs demonstrate the variability of the network from ideal conditions to actual conditions. The network topologies closer to the upperleft corner represent ideal conditions, and the network topologies closer to the lower-right corner represent actual conditions.

This theoretical model provides the basic topology of a biomass CHP plant network under various possible conditions. The heat transmission threshold $T$ is an important parameter in this model, and the energy utilization efficiency can be improved by identifying the optimal value of $T$. Considering the interference factors, the weather can affect its value on heat loss, and the territory can affect its value on the pipeline length. The research object of this article is chosen in the northeast of China, which has harsh winters and flat terrain, but this region has the highest food production among all provinces. Thus, the most severe status of heat loss and plain terrain becomes the premise condition for this paper. The Design Code for Heating Networks in China specifies the optimal heat pipe lengths in various regions of China. When the location is confirmed to be in Heilongjiang province, the heat pipe length from a CHP plant to a consumer is 6 to $8 \mathrm{~km}$ and should not exceed $10 \mathrm{~km} .{ }^{18} \mathrm{~A}$ study by Blaschke et al. concluded that the heat transmission distance should not exceed $10 \mathrm{~km} .{ }^{9}$ Kavvadias et al. developed a model to identify the maximal economically feasible transmission distance that meets a specified economic criterion and to derive a "rule of thumb" equation. ${ }^{19}$ Wang et al. designed a simulated model to calculate heat transmission loss, and a linear relation between the pipeline length and heat loss was obtained. ${ }^{20}$ Based on these results, a reasonable value for the heat transmission threshold would be 6 to $10 \mathrm{~km}$. However, a general range is not useful for design. In this study, a use case was selected, and GIS software was employed to evaluate threshold values in the range of 6 to $10 \mathrm{~km}$ to determine the value of the heat transmission threshold that maximizes the total energy utilization efficiency of a biomass CHP plant network.

The theoretical network model assumes that the communities are agricultural and situated on the flat terrain. Therefore, the use case was selected to meet these criteria. Heilongjiang province has a cold climate, flat terrain, and the highest agricultural production in China. ${ }^{21}$ The raw biomass material available in this region is primarily agriculture byproducts, and the total capacity is approximately $90.346 \times 10^{6} \mathrm{t}$ of standard coal. ${ }^{22}$ Ma and Zhang ${ }^{17}$ estimated that the annual volume of exploitable biomass is approximately $20.028 \times 10^{6} \mathrm{t}$ of standard coal according to various crop output quantities and heat values. In his research, a theoretical premise is set that $30 \%$ of all biomass energy can be used by reasonable means of straw collection. Biomass has enormous potential in Heilongjiang province. The current percentages of energy consumption by sources in Heilongjiang province are shown on the left-hand side of Fig. 4. It can be observed that the primary sources of energy currently are coal and oil. If biomass energy is developed based on the aforementioned ratio, biomass could replace coal for heating and a portion of the power generation in rural areas in winter shift the energy consumption to the proportions shown on the right-hand side of Fig. 4. Figure 4 shows that Heilongjiang province could greatly benefit from biomass energy development.

\section{GIS analysis of the use case}

Tongjiang is a county-level administrative division located on the Sanjiang plain in the northeast of Heilongjiang province between $132^{\circ} 18^{\prime} 32^{\prime \prime}$ and $134^{\circ} 7^{\prime} 15^{\prime \prime}$ east longitude and between $47^{\circ} 25^{\prime} 47^{\prime \prime}$ and $48^{\circ} 17^{\prime} 20^{\prime \prime}$ north latitude, with a total area of $6300 \mathrm{~km}^{2}$. The county includes five towns, five villages, six state-owned farms, and a total population of $210000 .^{23}$ 


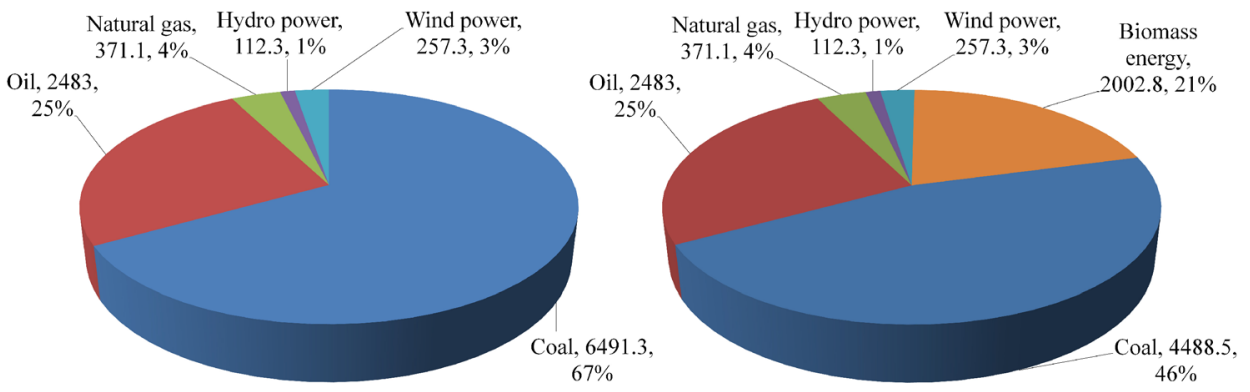

FIG. 4. Heilongiiang energy consumption: current (left) and with biomass energy development (right).

Tongjiang is a typical agricultural region that meets the criteria for the biomass CHP plant network model and was therefore selected as the use case for this study.

Assuming that the heat distribution pipes and the electric power lines run parallel to the road system, ArcGIS was employed to perform a network analysis using the road system in Tongjiang. The heat transmission threshold zoning analysis is shown in Fig. 5. The shading indicates the distances to each village and town; that is, the colors indicate the regions where the heat transmission threshold is in the ranges of $0-1 \mathrm{~km}, 1-2 \mathrm{~km}, \ldots>10 \mathrm{~km}$. The darker colors represent the lower values of the heat transmission threshold, indicating that a biomass CHP plant constructed in this vicinity would have lower heat transmission losses and higher economic efficiency. According to zoning analysis in Fig. 5, the scope of site selection is narrowed to the regions with the colors darker than $10 \mathrm{~km}$, and this is very conducive to improving the subsequent simulation analysis efficiency.

Because the government statistics are reliable and GIS software is readily available (GIS data were obtained from the Bureau of Surveying and Mapping of Heilongjiang province), this analysis method is applicable elsewhere. In other words, the heat transmission threshold zoning analysis based on government statistics and GIS software is applicable not only to Tongjiang but also to other areas.

\section{RESULTS: GOVERNING FACTORS AND PLAN COMPARISON}

In addition to the heat transmission threshold zoning analysis, the major factors influencing energy utilization efficiency were investigated. In the following sections, three factors affecting

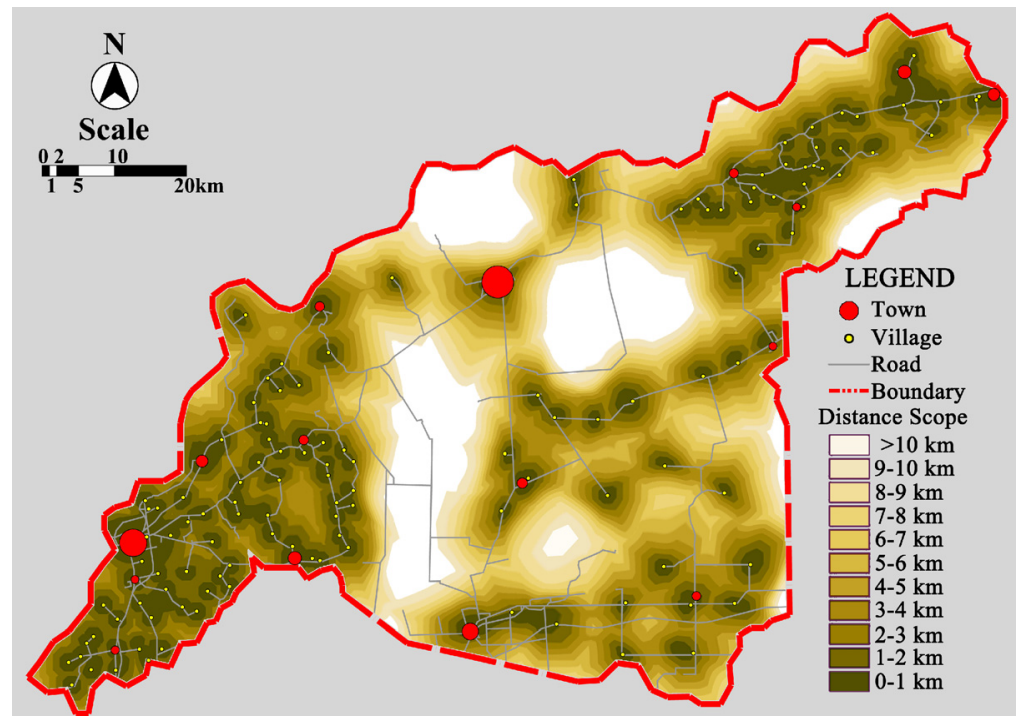

FIG. 5. Zoning analysis of the thermal energy transmission threshold. 
energy utilization efficiency - energy demand distribution, heat and electricity output efficiency, and heat and electricity transmission losses ${ }^{24}$-are analyzed. Various heat transmission thresholds were chosen, and biomass CHP plant networks with various distribution densities were generated. The energy utilization efficiency of each plan was calculated. The biomass CHP plant network plan with the highest energy utilization efficiency was used to determine the best value of the heat transmission threshold.

\section{A. Energy demand distribution}

The energy demand distribution essentially determines the number of biomass CHP plants and the gross power generation capacity in a region. ${ }^{25-27}$ Therefore, in this research, the CHP plant gross power was calculated based on population data and local per capita energy consumption. ArcGIS was employed to process the population data, geographical distribution, and road network in the region of interest to obtain the population distribution, which is shown in Fig. 6. This figure provides the population distribution data for the region, which was combined with the local resident annual per capita electricity consumption $(537 \mathrm{kWh} /$ year) to determine the gross power capacity required for each biomass CHP plant in the theoretical network. Therefore, accurate data are available for simulation and design to plan biomass CHP plant networks.

The values shown in Figs. 5 and 6 were superimposed, and service was limited to be within $500 \mathrm{~m}$ of a road, and so, a network of 1-km-wide branches (centered about the roads) was obtained, as shown in Fig. 7. Sections within the 1-km-wide network were classified based on the analysis, with darker shades indicating the areas where biomass CHP plant construction would be most effective. These networks can provide guidance for subsequent planning.

\section{B. Heat and electricity output efficiency}

Because plant heat output efficiency and electricity output efficiency are calculated from the energy conversion efficiency and the heat-electricity ratio, the former two factors should be considered simultaneously. Research on biomass CHP plant energy conversion efficiency by Lu and $\mathrm{Xi}^{11}$ and Kumar et al. ${ }^{13}$ showed that the energy conversion efficiency initially increases with increasing plant production capacity but levels off when the plant gross power capacity reaches $2.5 \mathrm{MWh}$. Studies by Zhang and Kang, ${ }^{12}$ Dai et al. ${ }^{28}$ and Liu et al. ${ }^{29}$ on biomass CHP plant generators showed that the heat-electricity ratio (the ratio of power plant heat output to

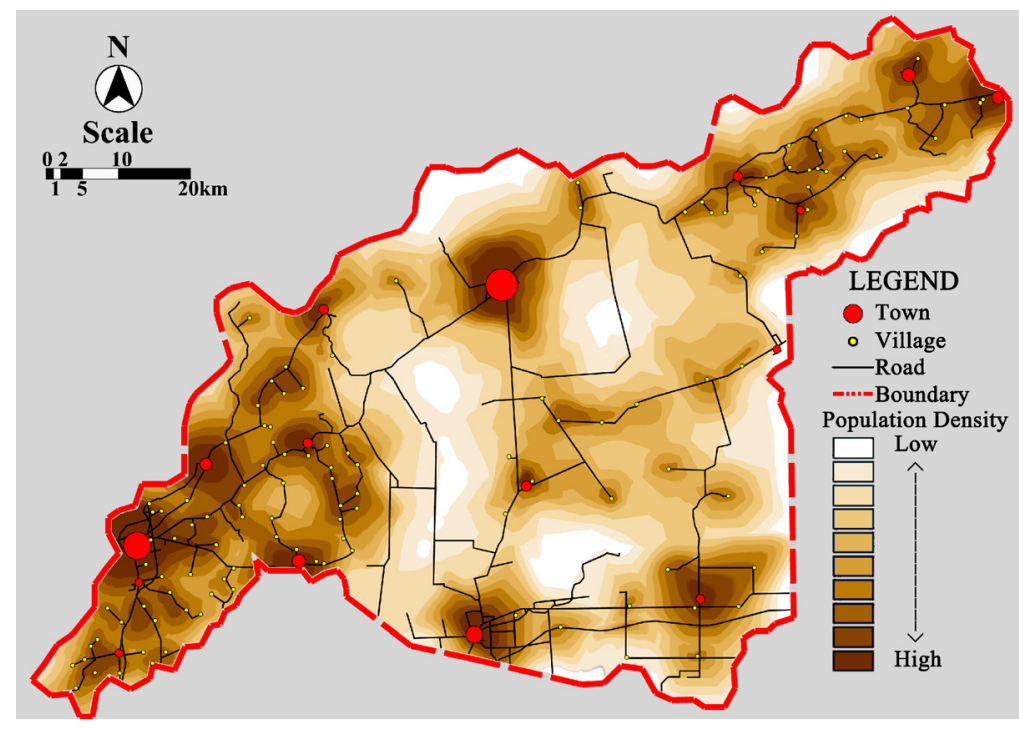

FIG. 6. Population distribution. 


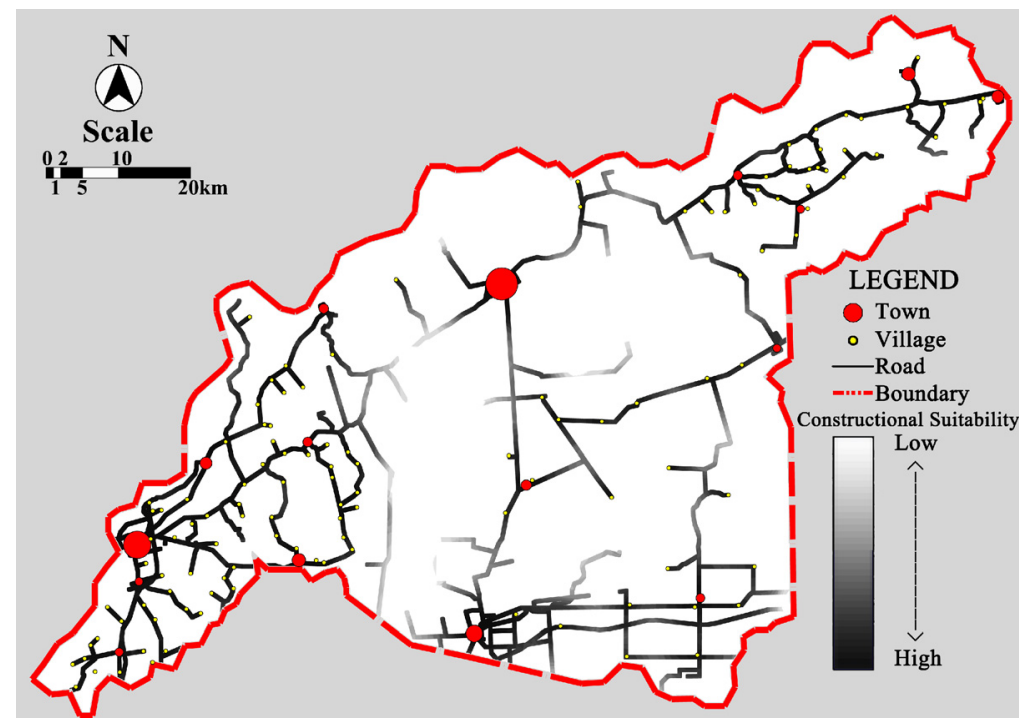

FIG. 7. Tongjiang biomass thermal power plant feasible construction zone distribution.

electricity output) initially decreases as the plant gross power increases but levels off when the gross power reaches $5 \mathrm{MW} \mathrm{h}$. The results of these studies are graphed in Fig. 8 .

Based on Fig. 8, the energy conversion efficiency, electricity conversion efficiency, and heat-electricity ratio were combined to obtain a function for the biomass CHP plant gross power capacity and the heat and electricity output efficiency. This function is plotted in Fig. 9. The graph shows that the plant heat output efficiency reaches a peak when the plant gross power is approximately $2.5 \mathrm{MWh}$. The heat output ratio exhibits a sharp initial rise and a gradual decline as the capacity increases. The electricity output efficiency exhibits a sharp initial rise followed by a more gradual rise as the capacity increases. This graph does not necessarily indicate that a small-scale (low-capacity) plant is more economical. Rather, the graph indicates that a small-scale plant has high heat output efficiency but low electricity output efficiency, whereas a large-scale (high-capacity) plant has low heat output efficiency but high electricity output efficiency.

\section{Heat and electricity transmission losses}

In this section, an analysis is performed of the heat distribution network loss rates for Heilongjiang province. The distribution network heat loss rate and the thermal supply distance

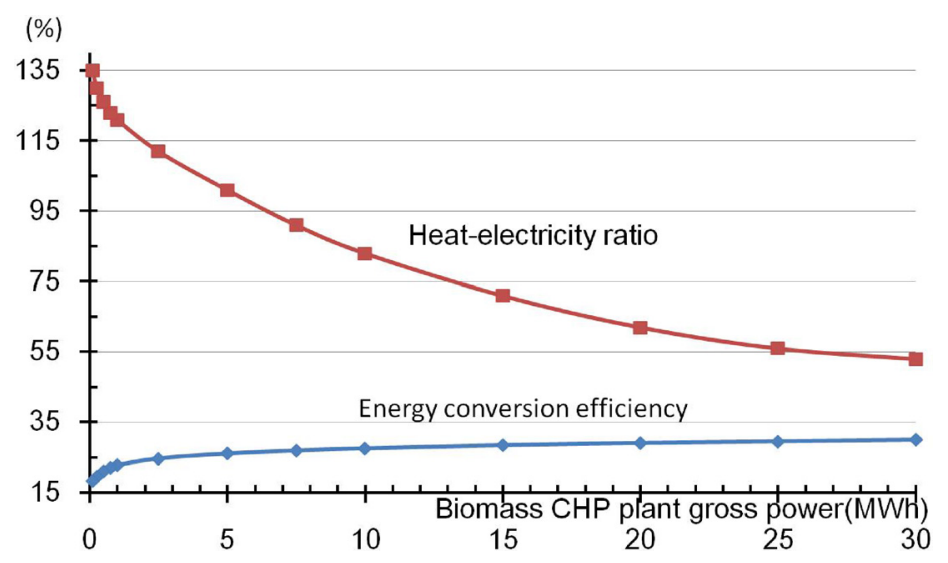

FIG. 8. Energy conversion efficiency and heat-electricity ratio versus biomass CHP plant gross power. 
(\%)

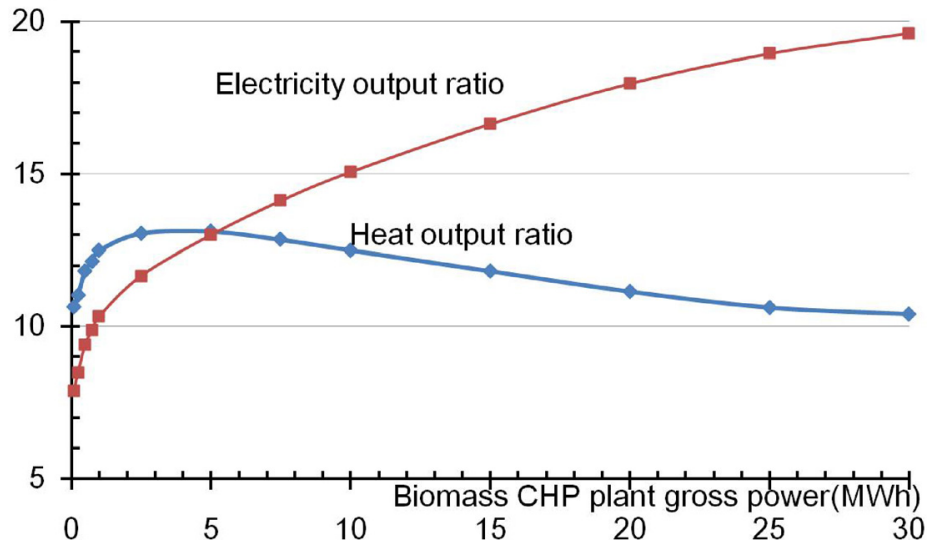

FIG. 9. Heat output efficiency and electricity output efficiency versus biomass CHP plant gross power.

are directly related. As shown in Table I, when the thermal supply distances are 6, 8, and $10 \mathrm{~km}$, the distribution network heat loss rates are $1.01 \%, 1.35 \%$, and $1.69 \%$, respectively. The heat transmission losses for various plans were calculated based on these values.

The electricity network line loss rate in Heilongjiang province was calculated to be $5 \%$ of the average annual electricity line losses based on historical data obtained from the electric utility. ${ }^{22}$

\section{Determination of the value of the heat transmission threshold}

Sections III A-IIIC examined the properties of the energy demand distribution, heat and electricity output efficiencies, and heat and electricity transmission losses. However, when analyzing the combined effects of these factors on the energy utilization efficiency, the results cannot be obtained directly. Using the heat transmission threshold range analysis in Sec. II A and the heat transmission threshold zoning analysis in Fig. 4, the heat transmission threshold was set to 6,8 , and $10 \mathrm{~km}(6 \mathrm{~km}$ and $10 \mathrm{~km}$ are the extreme values, and $8 \mathrm{~km}$ is the median value). After analyzing the data with ArcGIS, the three biomass CHP plant network plans shown in Fig. 10 were generated. The plan with the highest total energy utilization efficiency was identified.

Based on research results of $\mathrm{Lu}$ and $\mathrm{Xi}$, Kumar et al., and Dornburg and Faaij, ${ }^{11,13,30}$ some comprehensive formulas are obtained to calculate the energy utilization efficiency $H_{g}$ for each biomass CHP plant network plan, as follows:

$$
H_{g}=\frac{F\left[\left(1-L_{h}\right) \sum_{i=1}^{n} G_{i} H_{i}+\left(1-L_{e}\right) \sum_{i=1}^{n} G_{i} E_{i}\right]}{\sum_{i=1}^{n} G_{i} T_{i}},
$$

TABLE I. Relationship between the thermal supply distance and thermal losses.

\begin{tabular}{lcc}
\hline \hline Thermal supply distance $(\mathrm{km})$ & Pipe network thermal loss rate $(\%)$ & Thermal loss cost $\left(10^{4}\right.$ Yuan $)$ \\
\hline 2 & 0.34 & 58.60 \\
4 & 0.68 & 117.19 \\
6 & 1.01 & 175.79 \\
8 & 1.35 & 234.38 \\
10 & 1.69 & 292.98 \\
\hline \hline
\end{tabular}




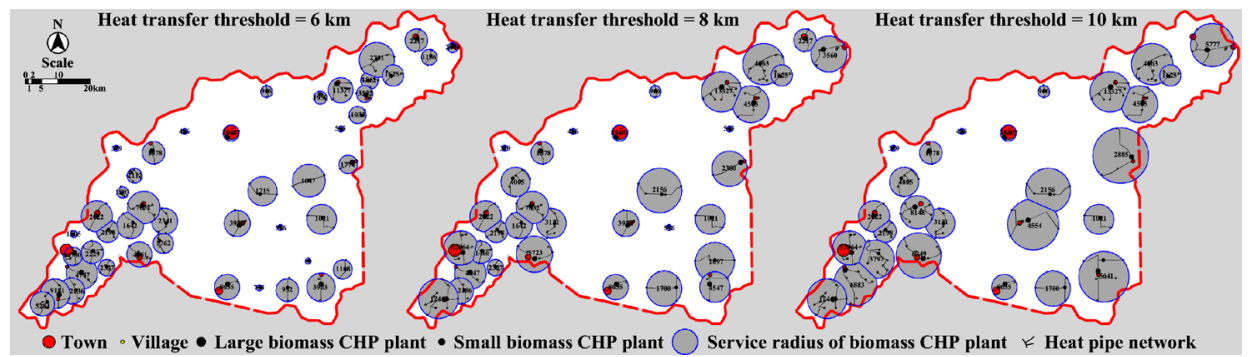

FIG. 10. Biomass CHP plant network plans with various heat transmission thresholds.

$$
G_{i}=P_{i} U, H_{i}=\frac{T_{i} R_{i}}{R_{i}+1}, E_{i}=\frac{T_{i}}{R_{i}+1},
$$

where $F$ is the plant load rate, $L_{h}$ is the heat distribution network loss rate, $L_{e}$ is the electricity network line loss rate, $G_{i}$ is the gross power output of plant $i(i=1,2,3 \ldots n), H_{i}$ is the heat output efficiency of plant $i, E_{i}$ is the electricity output efficiency of plant $i, P_{i}$ is the number of consumers served by plant $i, U$ is the annual per capita power consumption, $T_{i}$ is the energy conversion efficiency of plant $i$, and $R_{i}$ is the heat-electricity ratio of plant $i$.

Based on the average power consumption in Tongjiang, the plant load rate $F$ was set to $80 \%$. The heat distribution loss rate $L_{h}$ was based on Table I. The electric power network line loss rate was chosen to be $5 \%$ based on averages provided by the local electric utility. The plant gross power $G_{i}$ was calculated from the corresponding number of consumers $P_{i}$ and the per capita power consumption $U\left(537 \mathrm{kWh} /\right.$ year). The plant heat output efficiency $H_{i}$ and the electricity output efficiency $E_{i}$ were calculated from the plant energy conversion efficiency $T_{i}$ and the heat-electricity ratio $R_{i}$ (Fig. 7). The plant parameters for various heat transmission thresholds were calculated using Eqs. (1) and (2). The results are shown in Fig. 11. For heat transmission thresholds of 6,8 , and $10 \mathrm{~km}$, the number of CHP plants required in the region was 44,34 , and 27 , respectively. When the heat transmission threshold is small, the plant density is high, and there are more small CHP plants. When the heat transmission threshold is large, the plant density is low, and there are more medium-sized CHP plants (the population of Tongjiang is not sufficiently large to require large CHP plants).

Based on Eqs. (1) and (2), with heat transmission thresholds of 6,8 , and $10 \mathrm{~km}$, the total energy utilization efficiencies of the three candidate plant networks were calculated to be

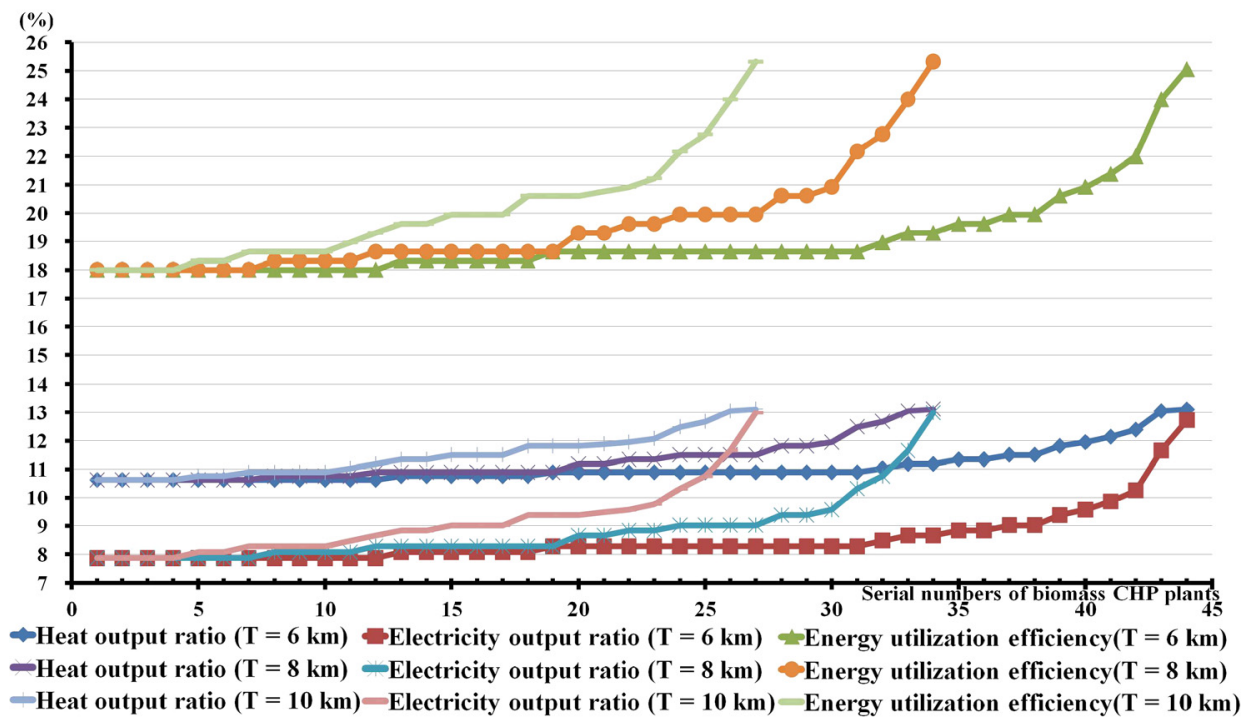

FIG. 11. Biomass thermal power plant efficiency indicators for various heat transmission thresholds. 

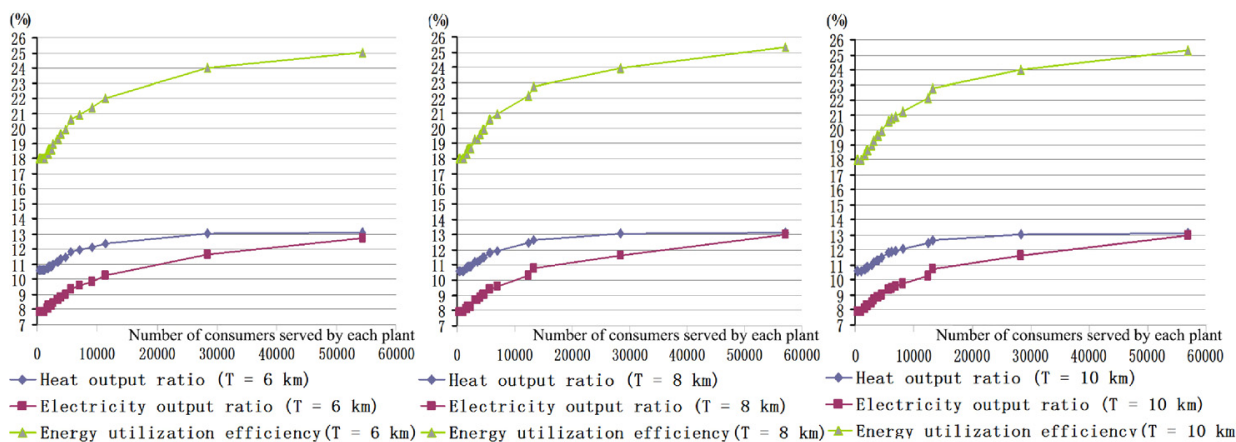

FIG. 12. Biomass CHP plant efficiency indicators versus number of consumers served for various heat transmission thresholds.

$21.6659 \%, 22.2234 \%$, and $22.4529 \%$. Judging from the analysis result, it is obvious that when the heat transmission threshold is $10 \mathrm{~km}$, the total energy utilization efficiency of the biomass CHP plant network is highest. This means that the planning scheme of biomass CHP plant networks can achieve the same effect with less heat energy and power energy, which is especially conducive to winter heating in cold regions. Therefore, the heat transmission threshold $T$ was chosen to be $10 \mathrm{~km}$. Greater total energy utilization efficiency in biomass CHP plant networks can be achieved using this value.

A study by Zhang and Kang ${ }^{12}$ on biomass CHP plant networks found that the heat utilization efficiency was higher for a heat transmission threshold of $8 \mathrm{~km}$. However, there were differences in the systems analyzed in that study. Zhang and Kang based their analysis on heat utilization efficiency, whereas the present study focused on total energy utilization efficiency. Therefore, the value of the heat transmission threshold that produced the best results was different. In practical applications, the selection of the heat transmission threshold should be based on the ratio of the heat and electricity demands in the region.

For heat transmission thresholds of 6,8 , and $10 \mathrm{~km}$, the heat output efficiency, electricity output efficiency, and energy utilization efficiency for various numbers of consumers were obtained, as shown in Fig. 12. It can be observed that the three parameters all increase with the increasing number of consumers. All three variables initially increase until the number of consumers served by a single plant reaches 25000 , and then, the rates of increase become lower. These results show that large biomass CHP plants have higher energy utilization efficiency. These results can assist in determining the proper size of CHP plants for a given number of consumers. The total energy utilization efficiency in the region will improve significantly when the number of consumers served by a plant exceeds 25000 .

In this study, a mathematical model for biomass CHP plant network topologies (Fig. 2) under various conditions (Fig. 3) was derived. The software program ArcGIS was employed to perform a heat transmission threshold zoning analysis (Fig. 5). The energy demand distribution was calculated based on the population distribution (Fig. 6). The generation capacity, heat and electricity conversion efficiencies, and heat-electricity ratio were used to calculate the heat and electricity output efficiencies (Figs. 8 and 9) and determine the heat transmission losses (Table I) and electricity transmission losses. Biomass CHP plant network plans were generated for heat transmission thresholds of 6, 8, and $10 \mathrm{~km}$ (Fig. 10). The results are compared in Figs. 11 and 12.

\section{CONCLUSIONS}

GIS software and population data were used to obtain a plan for the most efficient network of biomass CHP plants. This method can be used to improve biomass CHP plant network energy utilization efficiency and reduce the waste of resources.

1. A comparison of CHP plant network plans based on heat efficiency, electricity efficiency, and capacity showed that when the heat transmission threshold is small, the plant density is high 
and the size of the plants is smaller, and when the heat transmission threshold is large, the plant density is low and the size of the plants is larger.

2. A comparison of the energy utilization efficiencies for three network plans showed that for a heat transmission threshold of $10 \mathrm{~km}$, the plant network plan with the lowest density achieved the highest total energy utilization efficiency.

3. A previous study ${ }^{12,17,24}$ obtained the highest heat utilization efficiency for a heat transmission threshold of $8 \mathrm{~km}$, which differs from the value obtained in this study. The reason for this difference is that the criteria in the two studies were different (heat utilization efficiency versus total energy utilization efficiency). In practical applications, the selection of the heat transmission threshold should be based on the ratio of the heat and electricity demands in the service area.

4. A comparison of the population data and the energy utilization efficiencies for three plant network plans showed that when planning a biomass CHP plant network, the number of consumers served by each plant should exceed 25000 to maximize the total energy utilization efficiency of the system.

Although our research is not yet fully mature and systematic, it is gratifying that the attention of the local government has been captured. Using our results, Heilongjiang province plans to build and put into use 58 biomass CHP plants before 2020, which can generate 9 TW h every year. By the end of 2017, six plants were built and put into use. This means that many research studies on biomass CHP plant networks still should be carried out with complex interference factors.

\section{ACKNOWLEDGMENTS}

This research was sponsored by the Natural Science Foundation of China, Grant No. 51578175.

${ }^{1}$ M. Guo, W. Song, and J. Buhain, "Bioenergy and biofuels: History, status, and perspective," Renewable Sustainable Energy Rev. 46(6), 218-235 (2015).

${ }^{2}$ N. Scarlat, J. Dallemand, F. Monforti-Ferrario et al., "The role of biomass and bioenergy in a future bioeconomy: Policies and facts," Environ. Dev. 15(7), 3-34 (2015)

${ }^{3}$ National Bureau of Statistics of the People's Republic of China, China's Power Industry in-Depth Analysis and Market Research Report (2015-2020) (China Statistics Press, Beijing, 2016), p. 72.

${ }^{4}$ N. Scarlat, J. Dallemand, F. Monforti-Ferrario et al., "Renewable energy policy framework and bioenergy contribution in the European Union: An overview from National Renewable Energy Action Plans and Progress Reports," Renewable Sustainable Energy Rev. 51(11), 969-985 (2015).

${ }^{5}$ G. L. Zhao, "Assessment of potential biomass energy production in China towards 2030 and 2050," Int. J. Sustainable Energy 37(1), 47-66 (2018).

${ }^{6}$ C. F. Rosillo, "A review of biomass energy-shortcomings and concerns," J. Chem. Technol. Biotechnol. 91(7), 1933-1945 (2016).

${ }^{7}$ W. Chen, B. Lin, M. Huang et al., "Thermochemical conversion of microalgal biomass into biofuels: A review," Bioresour. Technol. 184(5), 314-327 (2015).

${ }^{8}$ F. Göran, "Biomass energy transport Analysis of bioenergy transport chains using life cycle inventory method," Biomass Bioenergy 19(1), 17-30 (2000).

${ }^{9}$ T. Blaschke, M. Biberacher, S. Gadocha, and I. Schardinger, “'Energy landscapes': Meeting energy demands human aspirations," Biomass Bioenergy 55(8), 3-16 (2013).

${ }^{10} \mathrm{X}$. Shi, A. Elmore, X. Li et al., "Using spatial information technologies to select sites for biomass power plants: A case study in Guangdong Province, China," Biomass Bioenergy 32(1), 35-43 (2008).

${ }^{11} \mathrm{C}$. $\mathrm{Lu}$ and $\mathrm{L}$. Xi, "Economic analysis of heating network's heating distance," China Science Technol. Inf.18(11), 223-224 (2011).

${ }^{12}$ Y. Zhang and J. Kang, "Effects of the distribution density of a biomass combined heat and power plant network on heat utilisation efficiency in village-town systems," J. Environ. Manage. 202(8), 21-28 (2017).

${ }^{13}$ A. Kumar, J. Cameron, and P. Flynn, "Biomass power cost and optimum plant size in western Canada," Biomass Bioenergy 24(6), 445-464 (2003).

${ }^{14} \mathrm{M}$. Biberacher and S. Gadocha, "GIS based model to optimize the utilization of renewable energy carriers and related energy flows," in 18th World IMACS Congress and MODSIM09 International Congress on Modelling and Simulation (Modelling and Simulation Society of Australia and New Zealand and International Association for Mathematics and Computers in Simulation, Australia-Canberra, 2009), pp. 1915-1921.

${ }^{15}$ T. Blaschke, M. Biberacher, S. Gadocha et al., "Virtual power plants: Spatial energy models in times of climate change," in Proceeding of Digital Earth Summit on Geoinformatics (Wichmann-Verlag, Germany-Heidelberg, 2008), pp. 61-66.

${ }^{16} \mathrm{~W}$. Wang, J. Xu, T. Yang et al., Urban Transportation Planning Theory and Application (Southeast University Press, Nanjing, 1998)

${ }^{17} \mathrm{~K}$. Ma and Y. Zhang, "Spatial planning pattern of biomass energy developing network in Heilongjiang province's village-town system,” Urban Dev. Stud. 23(6), 15-18 (2016). 
${ }^{18}$ Y. Zhang, G. Tian, Y. Sun et al., "Comparison of network heat loss rate between steam centralized heat-supply and hot water centralized heat-supply," Gas Heat 28(5), 13-16 (2008).

${ }^{19}$ K. Kavvadias, C. Konstantinos, and S. Quoilin, "Exploiting waste heat potential by long distance heat transmission: Design considerations and techno-economic assessment," Appl. Energy 216(4), 452-465 (2018).

${ }^{20}$ J. Wang, W. Gu, S. Lu et al., "Collaborative planning of multi-regional integrated energy systems with the heat network model," Autom. Electr. Power Syst. 40(8), 17-24 (2016).

${ }^{21}$ National Bureau of Statistics of the People's Republic of China, China Statistical Yearbook (China Statistics Press, Beijing, 2016), p. 261

${ }^{22}$ Heilongiang's Bureau of Statistics, Heilongjiang's Statistical Yearbook (China Statistics Press, Beijing, 2016), pp. 119-209.

${ }^{23}$ Fujin Bureau of Statistics, Fujin Statistical Yearbook (Fujin Bureau of Statistics, 2016), p. 26.

${ }^{24}$ Y. Zhang, T. Zhao, and K. Ma, "Improving spatial planning under perspective of energy landscape: Research on development strategy of biomass energy in Heilongjiang Province," Urban Dev. Stud. 21(9), 1-4 (2014).

${ }^{25}$ B. Hayes and M. Prodanovic, "State forecasting and operational planning for distribution network energy management systems," IEEE Trans. Smart Grid 7(3), 1002-1011 (2016).

${ }^{26}$ S. Sami, M. Cheng, J. Wu et al., "A virtual energy storage system for voltage control of distribution networks," CSEE J. Power Energy Syst. 4(6), 146-154 (2018).

${ }^{27}$ M. Liu, Y. Zhong, and J. Tan, "Impact of urban planning indicator on spatial distribution of residential heating and cooling energy demand," in 10th International Symposium on Heating, Ventilation and Air Conditioning, ISHVAC2017, Jinan, People's Republic of China (2017), Vol. 205, pp. 959-966.

${ }^{28}$ J. Dai, G. Liu, T. Xu et al., "Research on heat-electricity ratio's affecting factors of heating unit," Huadian Technol.35(12), 7-11 (2013).

${ }^{29}$ L. Liu, B. Han, and R. Zhang, "Heating's economic analysis for CHP units based on heat-electricity ratio," Dist. Heat. 36(1), 64-66 (2010).

${ }^{30}$ V. Dornburg and A. P. C. Faaij, "Efficiency and economy of wood-fired biomass energy systems in relation to scale regarding heat and power generation using combustion and gasification technologies," Biomass Bioenergy 21(2), 91-108 (2001). 